\title{
Article \\ Differentiation of Dental Pulp Stem Cells on Gutta-Percha Scaffolds
}

\author{
Liudi Zhang ${ }^{1}$, Yingjie Yu ${ }^{1}$, Christopher Joubert ${ }^{2}$, George Bruder ${ }^{2,3}$, Ying Liu ${ }^{4}$, \\ Chung-Chueh Chang ${ }^{4}$, Marcia Simon ${ }^{5}$, Stephen G. Walker ${ }^{5}$ and Miriam Rafailovich ${ }^{1, *}$
}

1 Department of Materials Science and Engineering, Stony Brook University, Stony Brook, NY 11794, USA; zldzld266@yahoo.com (L.Z.); yuyingjie312@gmail.com (Y.Y.)

2 Department of Endodontics, School of Dental Medicine, Stony Brook University, Stony Brook, NY 11794, USA; christopher.joubert@gmail.com

3 Department of Restorative Dentistry and Biomaterials Sciences, Harvard School of Dental Medicine, Harvard University, Boston, MA 02115, USA; George_Bruder@hsdm.harvard.edu

4 Advanced Energy Research \& Technology Center, Stony Brook University, Stony Brook, NY 11794, USA; Ying.Liu.1@stonybrook.edu (Y.L.); chung-chueh.chang@stonybrook.edu (C.-C.C.)

5 Department of Oral Biology and Pathology, School of Dental Medicine, Stony Brook University, Stony Brook, NY 11794, USA; Marcia.Simon@stonybrookmedicine.edu (M.S.);

Stephen.Walker@stonybrookmedicine.edu (S.G.W.)

* Correspondence: Miriam.Rafailovich@stonybrook.edu; Tel.: +1-516-458-9011

Academic Editor: Jianxun Ding

Received: 8 April 2016; Accepted: 4 May 2016; Published: 13 May 2016

\begin{abstract}
Advances in treatment of tooth injury have shown that tooth regeneration from the pulp was a viable alternative of root canal therapy. In this study, we demonstrated that Gutta-percha, nanocomposites primarily used for obturation of the canal, are not cytotoxic and can induce differentiation of dental pulp stem cells (DPSC) in the absence of soluble mediators. Flat scaffolds were obtained by spin coating Si wafers with three Gutta-percha compounds: GuttaCore ${ }^{\mathrm{TM}}$, ProTaper ${ }^{\mathrm{TM}}$, and Lexicon $^{\mathrm{TM}}$. The images of annealed surfaces showed that the nanoparticles were encapsulated, forming surfaces with root mean square (RMS) roughness of 136-211 nm. Then, by culturing DPSC on these substrates we found that after some initial difficulty in adhesion, confluent tissues were formed after 21 days. Imaging of the polyisoprene (PI) surfaces showed that biomineral deposition only occurred when dexamethasone was present in the media. Spectra obtained from the minerals was consistent with that of hydroxyapatite (HA). In contrast, HA deposition was observed on all Gutta-percha scaffolds regardless of the presence or absence of dexamethasone, implying that surface roughness may be an enabling factor in the differentiation process. These results indicate that Gutta-percha nanocomposites may be good candidates for pulp regeneration therapy.
\end{abstract}

Keywords: biomaterials; polymer nanocomposite; stem cells; cell differentiation; regeneration; cell-matrix interaction

\section{Introduction}

Root canal therapy is the most common endodontic procedure for preserving teeth without invasive surgery or dental implants [1,2]. It involves the removal of infected dental pulp, the subsequent shaping, cleaning of the hollows, and the obturation of the decontaminated canals with inert fillings such as Gutta-percha [3]. However, root canal treatment does not restore the biological function of the dental pulp tissue after significant damage $[4,5]$. Thus, it would be of great clinical benefit to develop a biologically based treatment to repair and regenerate the traumatized teeth, in order to both avoid surgical procedures and preserve the natural tooth. 
Recently, it has been shown that in children, where the injured tooth is permanent but immature, regeneration may be an attractive alternative treatment to obturation [6-8]. Obturation only maintains tooth structure, while the regeneration treatment aims to allow root elongation and thickening and thereby to restore full tooth function [9]. In this case, bleeding of the pulp is induced to promote angiogenesis and pulpal regeneration with various cells including fibroblasts and odontoblast progenitors or stem cells. Among human stem cells, dental pulp stem cells (DPSC) have relatively easy accessibility, fast multiplication rate, and multi-potential capability, thus could be used in clinic applications $[10,11]$. It has been reported that DPSC have possibility to repair bone defect in humans $[12,13]$. Therefore, as undifferentiated mesenchymal stem cells, DPSC may be good candidates to study stem cell regenerative therapies.

Scaffolds may also be inserted to further activate and support the requisite stem cells of the pulp. There have been many reports on potential scaffolds for dental pulp regeneration, based on their ability to promote in vivo and in vitro DPSC differentiation with additional chemical inducers [14-16]. However, the use of chemical inducers such as dexamethasone corticosteroid in vivo may cause adverse side effects and weaken human immune system [17]. Recently Chang et al. have shown that polybutadiene, a polymer with similar chemistry to polyisoprene (PI), the base material of Gutta-percha, was able to induce differentiation of DPSC when the mechanical properties were properly adjusted [18]. Here we aim to explore whether Gutta-percha materials can also be appropriate scaffolds for the delivery and differentiation of DPSC without additional induce factors.

Gutta-percha is a trans-1,4-polyisoprene based nanocomposite, where the average molecular weight of the PI matrix was found to be 42,000 [19]. Because of the low glass transition temperature of PI, $T_{g}=-40{ }^{\circ} \mathrm{C}$, inorganic fillers are added to reinforce the mechanical properties [20,21]. Since bacterial infection is always a concern in root canal therapy, Zinc Oxide $(\mathrm{ZnO})$ is often the particle of choice due to its well-known anti-microbial properties [22-24]. However, it has been demonstrated by several groups that $\mathrm{ZnO}$ nanoparticles are cytotoxic to eukaryotic cells [25-27]. Leakage of $\mathrm{ZnO}$ nanoparticles was suspected as an early source of cytotoxicity which became apparent after $24 \mathrm{~h}$ incubation of fourteen Gutta-percha materials commercially available prior to 1990 [28]. More recently though, Gambarini et al. showed no cytotoxicity up to $72 \mathrm{~h}$ to periodontal ligament cells of newer root canal filling materials [29]. No study has addressed as yet the influence of Gutta-percha on stem cells differentiation. Furthermore, if low level $\mathrm{ZnO}$ leakage remains a problem, it is important to determine cytotoxicity in culture for at least 21 days, or the time known to affect differentiation and biomineralization of DPSC.

In this paper, we address this question by using three types of Gutta-percha: GuttaCore ${ }^{\mathrm{TM}}$, ProTaper $^{\mathrm{TM}}$, and Lexicon ${ }^{\mathrm{TM}}$. Flat scaffolds were made by spin coating Si wafers with Gutta-percha nanocomposites to facilitate imaging. Even though these scaffolds are for in vitro work only, they are useful for determining properties relevant to in vivo situation. In order to investigate their potential for supporting tooth regeneration, we first characterize the nanoparticles and their distribution using scanning electron microscopy/energy dispersive analysis X-ray spectroscopy and scanning probe microscopy. We then probe the anti-bacterial properties and the response of DPSC cultured on these scaffolds for 21 days with and without dexamethasone.

\section{Materials and Methods}

\subsection{Materials}

GuttaCore $^{\mathrm{TM}}$, ProTaper ${ }^{\mathrm{TM}}$, and Lexicon ${ }^{\mathrm{TM}}$ (all from DENTSPLY International, Inc., Johnson City, TN, USA) were used in this study. ProTaper ${ }^{\mathrm{TM}}$ and Lexicon ${ }^{\mathrm{TM}}$ are uncrosslinked regular Gutta-percha cones, while GuttaCore ${ }^{\mathrm{TM}}$ includes crosslinked grey core and uncrosslinked pink coating. Inside core part of GuttaCore ${ }^{\mathrm{TM}}$ was carefully removed. All these three materials consist of an elastomeric polymer matrix, PI, loaded with inorganic nanoparticles to provide mechanical properties and radiopacity. These materials differ in their degree of loading, composition, and size of the 
nanoparticles. As manufacturer's specification, they all contain $20 \%-30 \%$ PI matrix and more than $50 \% \mathrm{ZnO}$ nanoparticles.

\subsection{Preparation of Gutta-Percha Scaffolds}

Silicon wafers (orientation (100), Wafer World, West Palm Beach, FL, USA), were cleaved into $1 \mathrm{~cm} \times 1 \mathrm{~cm}$ square, boiled in a mixed ammonia-peroxide solution $\left(\mathrm{H}_{2} \mathrm{O} / \mathrm{H}_{2} \mathrm{O}_{2} / \mathrm{NH}_{3} \mathrm{H}_{2} \mathrm{O}\right.$ 5:1:1 by volume) for $15 \mathrm{~min}$, and then boiled in piranha solution $\left(\mathrm{H}_{2} \mathrm{O} / \mathrm{H}_{2} \mathrm{O}_{2} / \mathrm{H}_{2} \mathrm{SO}_{4}\right.$ 3:1:1 by volume) for $15 \mathrm{~min}$. They were rinsed with deionized water, and immersed in hydrofluoric acid solution $\left(\mathrm{H}_{2} \mathrm{O} / \mathrm{HF}\right.$ 10:1) for $30 \mathrm{~s}$, to create a hydrophobic surface. ProTaper ${ }^{\mathrm{TM}}$, Lexicon ${ }^{\mathrm{TM}}$, and outside coating part of GuttaCore ${ }^{\mathrm{TM}}$ were dissolved in chloroform, and PI $\left(M_{\mathrm{W}}=803,000 \mathrm{Da}\right.$, polydispersity index $(\mathrm{PDI})=1.36$, Scientific Polymer Products, Ontario, NY, USA) was dissolved in toluene. All the solutions were spun cast onto hydrophobic Si wafers at $2500 \mathrm{rpm}$ for $30 \mathrm{~s}$, and then annealed at $130{ }^{\circ} \mathrm{C}$ in a vacuum of $10^{-3}$ Torr overnight to remove the residual solvent, sterilize, and relax strains induced by the spinning process.

\subsection{Scanning Electron Microscopy and Energy Dispersive Analysis X-ray (SEM-EDAX)}

The spun cast Gutta-percha scaffolds were sputtered with gold, and imaged with a LEO/Zeiss 1550 field emission SEM (Carl Zeiss, Thornwood, NY, USA) at $20 \mathrm{KeV}$ accelerating voltage using Robinson type backscattering electron detectors. The elemental compositions of the samples were determined using Phoenix EDAX system in conjunction with SEM.

\subsection{Scanning Probe Microscopy (SPM)}

Surfaces of the spun cast Gutta-percha scaffolds were assessed Bruker Dimension ICON SPM (Dimension 3000; SPM, Santa Barbara, CA, USA) scans. Both topographic (vertical scanning) and friction (lateral scanning) modes of SPM were used in this study.

\subsection{Antimicrobial Activity and Efficacy Test}

Ten $\mu \mathrm{L}$ Enterococcus faecalis ATCC 19433 was sandwiched between two layers of $38 \mathrm{~mm} \times 38 \mathrm{~mm}$ spun cast scaffolds or $29 \mathrm{~mm}$ diameter molded scaffolds, and incubated for $24 \mathrm{~h}$. The surfaces were then rinsed to remove bacteria and the rinse solution was plated to determine colony forming units. The number of live bacterial colonies was counted at the following day.

\subsection{Cell Isolation and Cell Plating}

Human DPSC (strain AX3, Passage 6) were obtained from the Department of Oral Biology and Pathology, Stony Brook University, Stony Brook, NY, USA. They were isolated from the third molar teeth (IRB\#20076778) as previously described [30] and cultured in "base media": alpha Minimal Essential Medium ( $\alpha$ MEM; Catalog \#12571, GIBCO, Invitrogen, Carlsbad, CA, USA) supplemented with 10\% fetal bovine serum (GIBCO, Invitrogen, Carlsbad, CA, USA), $100 \mathrm{units} / \mathrm{mL}$ penicillin $/ 100 \mu \mathrm{g} / \mathrm{mL}$ streptomycin (GIBCO, Invitrogen, Carlsbad, CA, USA), $200 \mu \mathrm{M}$ L-ascorbic acid 2-phosphate (Sigma Aldrich, St. Louis, MO, USA), and $10 \mathrm{mM} \beta$-glycerol phosphate (Sigma Aldrich, St. Louis, MO, USA). Osteogenic/odontogenic induction of the DPSC was achieved by addition of $10^{-8} \mathrm{M}$ dexamethasone (Dex) (Sigma Aldrich, St. Louis, MO, USA) and is termed "induction medium" [31]. Cells were grown in a humidified incubator at $37{ }^{\circ} \mathrm{C}$ with $5 \%(v / v) \mathrm{CO}_{2}$. Culture medium was refreshed every alternate day.

DPSC were seeded onto Gutta-percha and PI scaffolds at a density of $10,000 \mathrm{cells} / \mathrm{cm}^{2}$. The proliferation rates of DPSC grown in "base media" were determined on days 3, 6, 9, 12, and 15 by harvesting cells with Trypsin/EDTA (0.05\%/0.1\% in Hank's Balanced Salt Solution) and counting cells using a hemacytometer (Hausser Scientific, Horsham, PA, USA). We didn't specific the dead cells that may be attached to the scaffolds since they were also from proliferation. For the differentiation 
experiments, cells were cultured in both "base medium" and "induction medium". For detection of mineralization by SEM-EDAX, at day 21, cultures were taken out of incubator, washed with deionized water to remove salts, and dehydrated at room temperature.

\subsection{Confocal Laser Scanning Microscopy}

Surfaces with DPSC were washed with phosphate buffered saline (pH 7.4, Ca, Mg-free), fixed with $3.7 \%(w / v)$ formaldehyde, permeabilized with $0.4 \%$ Triton X100, and then stained with Alexa Fluor 488 Phalloidin (Molecular Probes, Eugene, OR, USA) for actin filaments and Propidium Iodide (Molecular Probes, Eugene, OR, USA) for nuclei. Samples were photographed using a Leica TCS SP2 laser scanning confocal microscope (Leica microsystem Inc., Bannockburn, IL, USA) to visualize actin cytoskeleton organization and morphology of the cells.

\section{Results}

Gutta-percha scaffolds were obtained by dissolving ProTaper $^{\mathrm{TM}}$, Lexicon ${ }^{\mathrm{TM}}$, and the outside coating of GuttaCore ${ }^{\mathrm{TM}}$ in chloroform and spin casting them onto Si wafers as thin films $(t \sim 1 \mu \mathrm{m})$. SEM-EDAX analysis of the films is shown in Figure 1a where we can see that all the samples has a high density of nanoparticles. The composition of the nanoparticles is primarily ZnO, while GuttaCore ${ }^{\mathrm{TM}}$ coating also has a significant Barium component. In Figure $1 \mathrm{~b}$ we image these surfaces with SPM, where the topographical images show particles embedded in polymer matrix, with root mean square (RMS) roughness of $186 \pm 22 \mathrm{~nm}, 136 \pm 8 \mathrm{~nm}$, and $211 \pm 30 \mathrm{~nm}$ for the GuttaCore ${ }^{\mathrm{TM}}$ Coating, ProTaper ${ }^{\mathrm{TM}}$, and Lexicon ${ }^{\mathrm{TM}}$, respectively. The distribution of the topographical features is consistent with that observed with SEM, namely particles are approximately $1 \mu \mathrm{m}$ in height and are packed closely together. Moreover, we show the lateral force scans of the surfaces in Figure 1b. These scans measure the lateral deflection of the SPM tip, which is an indicator of surface friction or tip adhesion. Since the PI matrix is much softer, its friction is expected to be higher than that of the much harder particles. Yet, the relative lack of contrast observed indicates that the particles are coated by the surrounding matrix. Therefore, our hypothesis is that Gutta-percha scaffolds won't exhibit anti-bacterial activity and cytotoxicity due to encapsulation of the $\mathrm{ZnO}$ nanoparticles.

Antimicrobial activity and efficacy test was performed to investigate the anti-bacterial properties of Gutta-percha scaffolds. Both spun cast and molded bulk samples were studied in order to eliminate possible artifacts in particle coating or distribution produced by spin casting process. PI spun coated Si wafer was used as control. The results are plotted in Figure 2. We can see that bacteria remained after $24 \mathrm{~h}$ incubation on molded scaffolds are almost at the same level as the beginning, while that on spun cast scaffolds are a little bit lower possibly due to the exposure of ZnO nanoparticles. In JIS Z 2801, the calculation of the value of antimicrobial activity is:

$$
R=[\log (B / A)-\log (C / A)]
$$

where, $R$ : value of antimicrobial activity. $A$ : average of the number of viable cells of bacteria immediately after inoculation on the untreated test piece. $B$ : average of the number of viable cells of bacteria on the untreated test piece after $24 \mathrm{~h}$. C: average of the number of viable cells of bacteria on the antimicrobial test piece after $24 \mathrm{~h}$. 

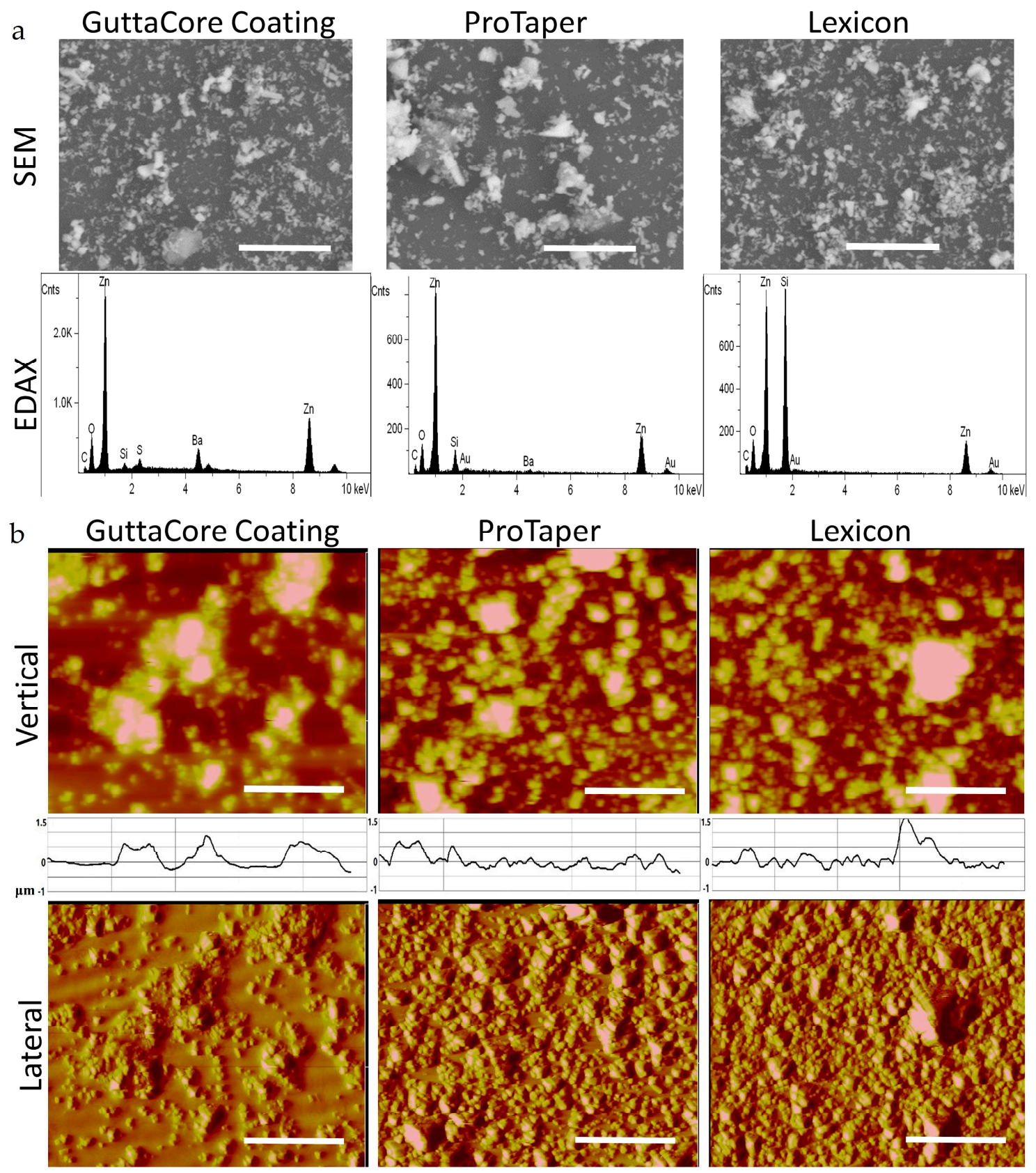

Figure 1. (a) Scanning Electron Microscopy (SEM) (top) images and Energy Dispersive Analysis X-ray (EDAX) (bottom) spectra obtained of the spun cast GuttaCore ${ }^{\mathrm{TM}}$ Coating, ProTaper ${ }^{\mathrm{TM}}$, and Lexicon ${ }^{\mathrm{TM}}$ thin $(\sim 1 \mu \mathrm{m})$ film surfaces. Scale bar is $5 \mu \mathrm{m}$; (b) Scanning Probe Microscopy (SPM) images in the topographical mode (top) and lateral force or friction mode (bottom) of the same surfaces as Figure 1a. Scale bar is $5 \mu \mathrm{m}$. Inset: One of the six cross sectional scans of the topographical images from which the root mean square (RMS) roughness was calculated. The Y-axis represents surface depth $(-1 \sim 1.5 \mu \mathrm{m})$.

According to the standard, the value of antimicrobial activity shall not be less than 2.0 for the antimicrobial efficacy. However, the value of all the tested Gutta-percha substrates is less than 2.0. Thus, none of the samples had significant anti-bacterial activity, which is consistent with previous reports [32,33]. 


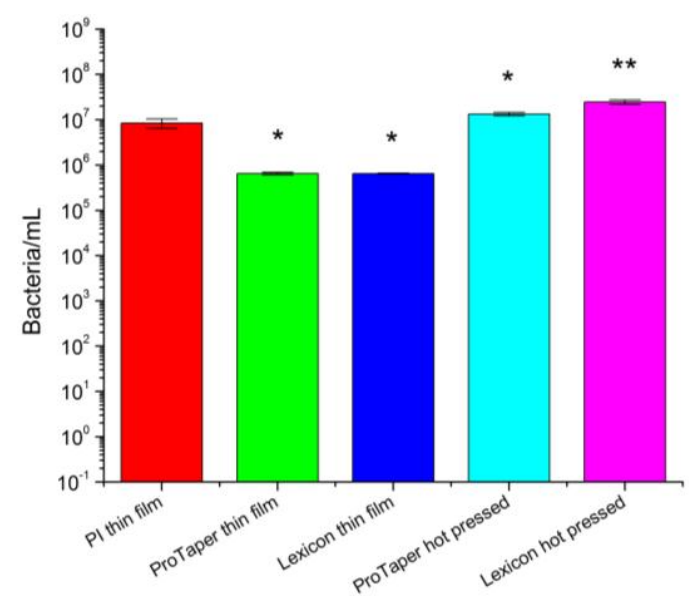

Figure 2. Antimicrobial activity and efficacy on ProTaper $^{\mathrm{TM}}$ and Lexicon ${ }^{\mathrm{TM}}$, which were both spun cast on Si substrates and molded. A quantity of $25 \mathrm{~nm}$ polyisoprene (PI) coated Si substrate was used as control. The Enterococcus faecalis concentration applied to the surfaces was 1E7 per mL. The figure represents the number of colony forming units recovered from the scaffolds after $24 \mathrm{~h}$ of exposure. The results differ from control at a statistical level of $\left.p>0.05{ }^{*}\right)$ and $p<0.05\left(^{* *}\right)$.

In order to determine whether the $\mathrm{ZnO}$ nanoparticles alone are cytotoxic, DPSC were plated on tissue culture plastic dishes for four days, till confluence was reached (see Figure 3a). On day 5, $0.05 \mathrm{mg} / \mathrm{mL}$ of $\mathrm{ZnO}$ nanoparticles were added to the media [26] and the cells were cultured for another $24 \mathrm{~h}$, after which they were fixed and stained with Alexa Fluor 488 Phalloidin and Propidium Iodide. The cells were then imaged with confocal microscopy, where many appear to be died, filling the plate with debris, and the remaining appears dendritic (Figure 3c). No change in the control sample was observed at day 6 (Figure 3b). These results showed that adding as low as $0.05 \mathrm{mg} / \mathrm{mL}$ of bare $\mathrm{ZnO}$ nanoparticles in media will prevent the normal proliferation process of cells, indicating that they are very cytotoxic to the DPSC.
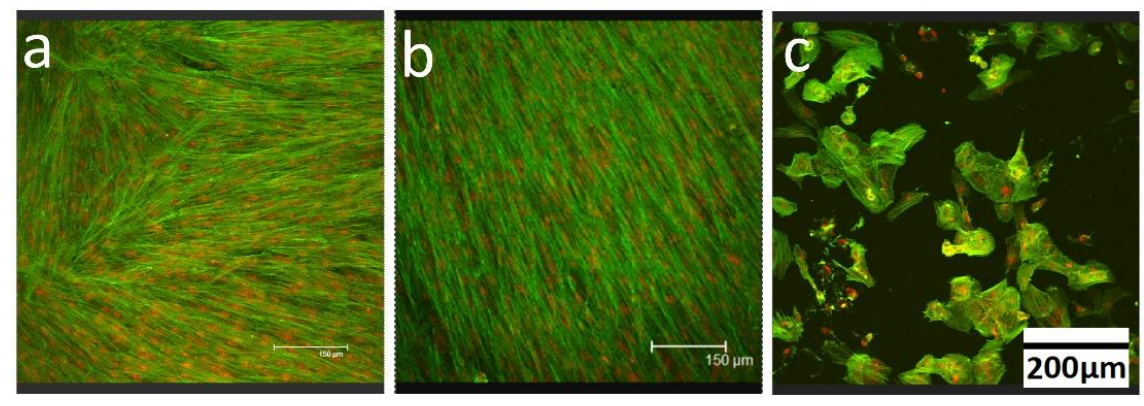

Figure 3. Dental pulp stem cells (DPSC) were plated on tissue culture plastic at a density of 10,000 cells $/ \mathrm{cm}^{2}$, stained with Alexa Flour 488 (green) for actin filaments and Propidium Iodide (red) for nucleus and imaged with confocal microscopy after being cultured for (a) 4 days; (b) 6 days; and (c) 6 days with $0.05 \mathrm{mg} / \mathrm{mL} \mathrm{ZnO}$ nanoparticles added at day 5 .

Then, spun cast Gutta-percha scaffolds, together with $25 \mathrm{~nm}$ PI thin films, were used to probe whether the $\mathrm{ZnO}$ nanoparticles in Gutta-percha are cytotoxic. DPSC were seeded at a density of $10,000 / \mathrm{cm}^{2}$ onto the scaffolds and cell proliferation rates were measured as a function of incubation time. The cell proliferation curves and doubling time calculations are shown in Figure 4a,b. From the figure we find that comparing to the PI control, the proliferation curves of the Gutta-percha scaffolds first show a lag where the proliferation rate is slower, but then the culture recovers and proliferates at nearly the same rate as the control. This result is consistent with the confocal microscopy images 
obtained at days 3 and 6 in Figure 4c. It is obviously that at day 3, the DPSC only formed a confluent sheet on the PI control sample, but not on any of the Gutta-percha scaffolds. In the inset of each figure we show a magnified view of the cells, where we can clearly see that the actin fibers are well extended only on PI. On the Gutta-percha scaffolds, the fibers are thin and not well extended. The cell areas are also much smaller. However, by day 6, the cells on all the Gutta-percha scaffolds appear to have recovered, and formed a confluent sheet. The morphology of the individual cells shown in the inset now appears similar to that of the cells on the control sample with well-defined actin fibers (Figure 4c, inset). This observation of Gutta-percha scaffolds demonstrates the lack of cytotoxicity towards ligament cells, together with the decreased anti-bacterial activity, support the hypothesis of encapsulation.

To further explore the potential application of Gutta-percha on pulp regeneration, the ability of DPSC to differentiate on these scaffolds was also probed. Cells were incubated with and without dexamethasone which is known to induce osteogenic/odontogenic differentiation of DPSC [31,34]. After 21 days in culture, the samples were imaged with confocal microscopy and examined using SEM-EDAX. From Figure 5a we can see that all cultures remained confluent for at least 21 days, indicating that there was no slow leakage of $\mathrm{ZnO}$ nanoparticles sufficient to be cytotoxic. The cultures with added dexamethasone produced biomineralized deposits, which EDAX confirmed as being composed of calcium phosphate, or hydroxyapatite (HA) (Figure 5b). Hence Gutta-percha scaffolds did not interfere with the standard differentiation process. On the other hand, it's interesting to note that differentiation, as defined by deposition of biomineralized HA products, was also observed on all of the Gutta-percha scaffolds without dexamethasone. Hence we can conclude that Gutta-percha is neither anti-bacterial nor cytotoxic and may promote DPSC differentiation in the absence of additional chemical factors.
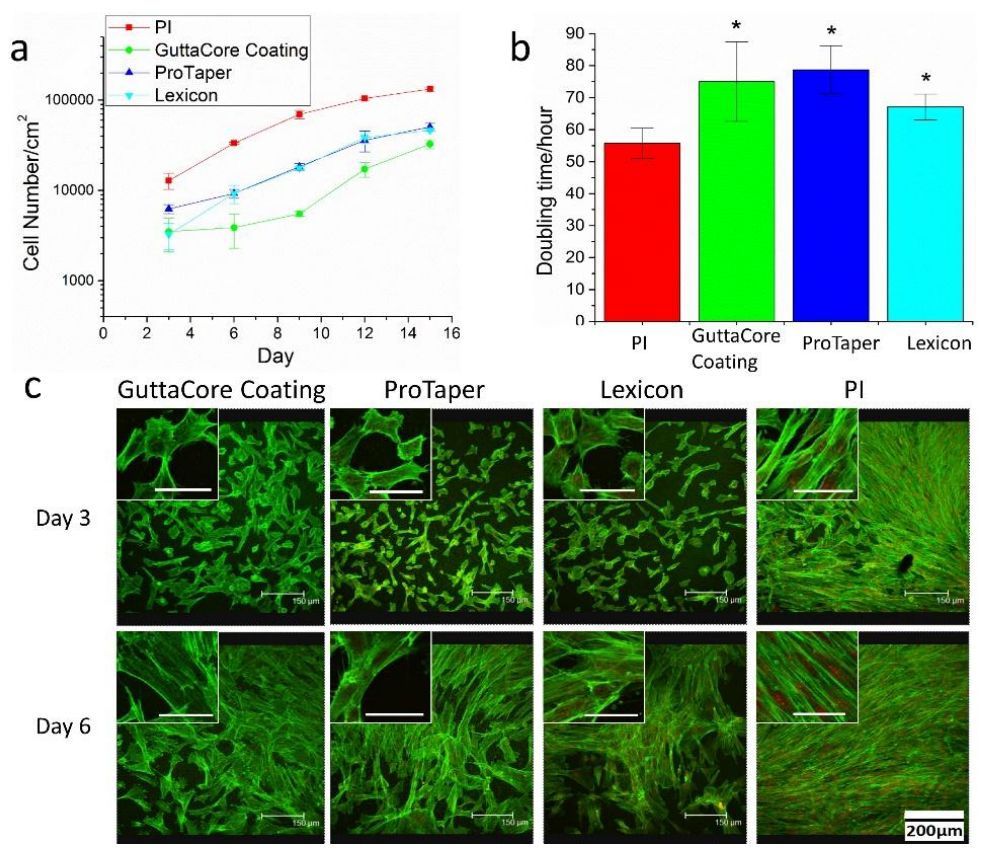

Figure 4. (a) Proliferation curves of DPSC plated, at an initial cell density of $10,000 / \mathrm{cm}^{2}$ on the Gutta-percha scaffolds (shown in Figure 1) and $25 \mathrm{~nm}$ spun cast PI thin films; (b) The doubling time of the DPSC calculated from the data plotted in (a). The Gutta-percha samples differ from control sample at a statistical level of $p>0.05\left(^{*}\right)$; (c) Confocal microscopy images of DPSC plated on PI and on the three Gutta-percha scaffolds after 3 and 6 days in culture without dexamethasone. Actin filaments were stained with Alex Flour 488 (green) and nucleus was stained with propidium iodide (red). Inset: High magnification images of individual cells in the cultures without dexamethasone (scale bar is $50 \mu \mathrm{m}$ ). 


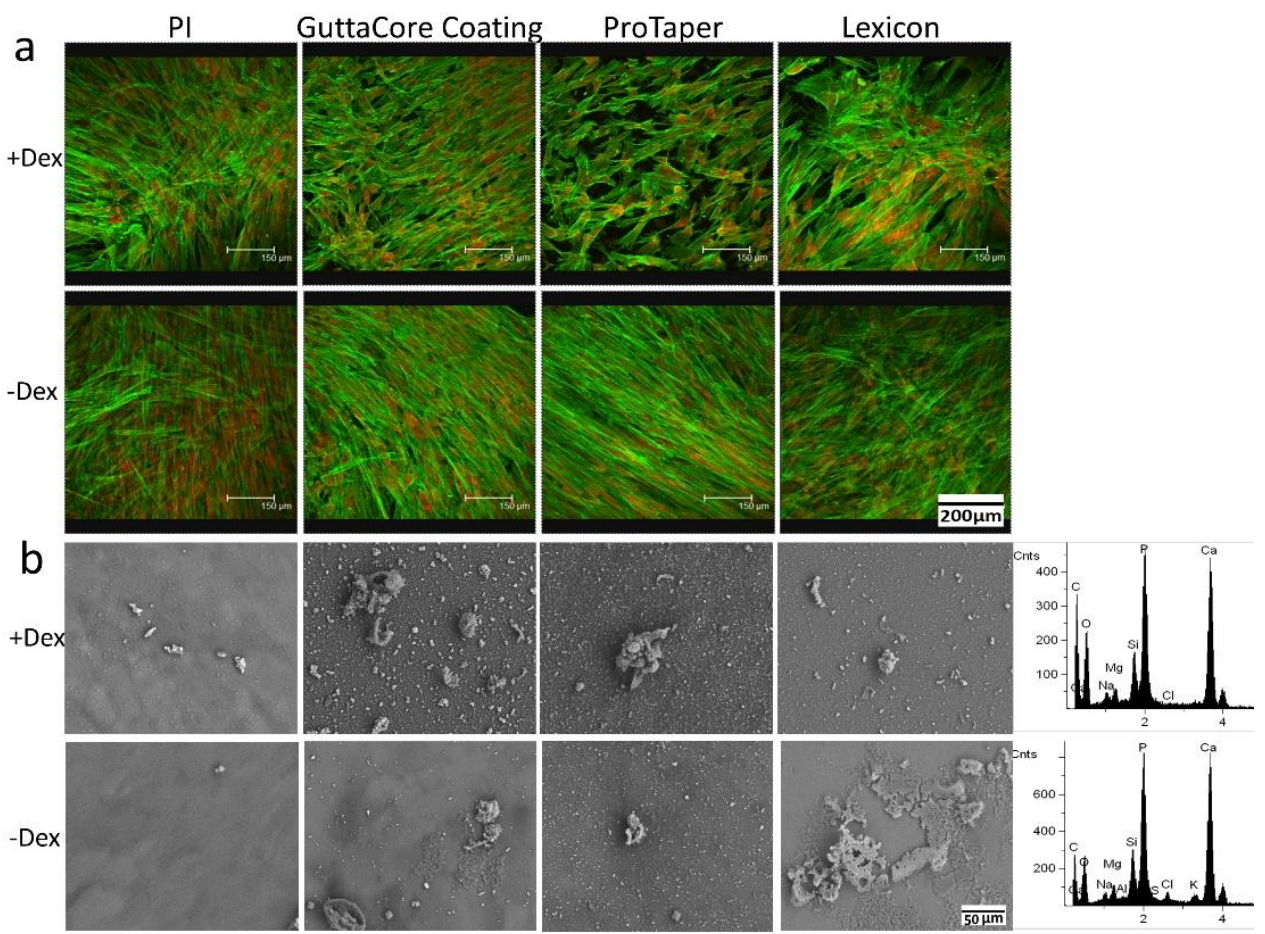

Figure 5. (a) Confocal microscopy images of the DPSC plated on scaffolds the same as Figure 4 and cultured for 21 days with (top) and without (bottom) addition of dexamethasone. Actin filaments were stained with Alex Flour 488 (green) and nucleus was stained with propidium iodide (red); (b) SEM images of the surfaces after rinsing with DI water and dehydration in air. The sidebar shows typical EDAX spectra obtained from the mineral deposits in the cultures with dexamethasone (top) and without dexamethasone (bottom).

\section{Discussion}

Gutta-percha materials were primarily designed for obturation of the canal. Consequently, they were mostly composed of an elastomeric polymer mixed with $\mathrm{ZnO}$ nanoparticles, whose function were primarily to provide anti-bacterial protection and mechanical reinforcement. Hence little attention was paid to their interaction with living tissues. More recently new therapies have been proposed, especially in children and adolescents, where injury to the tooth could be treated via regeneration of the pulp rather than obturation of the canal. Here we show that the same Gutta-percha materials used for obturation may also be suitable for tooth regeneration despite their large volume fraction of $\mathrm{ZnO}$ nanoparticles, which as expected, were shown to be cytotoxic when added directly into the culture media. Scaffolds obtained from the Gutta-percha materials maintained encapsulation of the $\mathrm{ZnO}$ nanoparticles within the polymer matrix. Although cells plated on these substrates initially showed lower plating efficiency and proliferation rate, after six days, the culture seemed to have recovered and the cells grew to confluence with a doubling time similar to that on the PI homopolymer.

DPSC were also cultured on Gutta-percha and PI scaffolds for 21 days with and without dexamethasone, a soluble factor known to induce osteogenic/odontogenic differentiation. Analysis of the PI surface after 21 days showed biomineralized deposits only on the cultures treated with dexamethasone. The DPSC cultured on the Gutta-percha scaffolds with dexamethasone also showed biomineralized deposits indicating that the $\mathrm{ZnO}$ nanoparticles did not interfere with the cell culture and standard cell differentiation even after three weeks. More interesting though was the observation of biomineralized deposits on the scaffolds where the cells were cultured without dexamethasone, indicating that those scaffolds were able to induce differentiation without additional chemical factors. The high toxicity of the bare $\mathrm{ZnO}$ nanoparticles and the fact that the DPSC were able to form a confluent sheet of tissue after 21 days precludes significant leakage of $\mathrm{ZnO}$ into the culture 
media. Hence we could make the model shown in Figure 6 of the Gutta-percha scaffolds, where large amounts of $\mathrm{ZnO}$ and/or Barium particles are fully encapsulated within the PI matrix. The major distinction then between the Gutta-percha samples and the control is the surface roughness measured with SPM topographical scans. Recently, Iaculli Flavia demonstrated that the probability of osteogenic differentiation of DPSC without chemical induction factors was increased on rough Titanium surfaces [35]. A similar phenomenon may also be occurring here, where the differentiation is induced simply by the surface roughness. In fact, the largest amount of HA, where the deposition has formed sheet like deposits is observed on the Lexicon ${ }^{\mathrm{TM}}$ scaffold, which also has the largest RMS roughness of $211 \pm 30 \mathrm{~nm}$, and while the least amount is observed on the ProTaper ${ }^{\mathrm{TM}}$ with an RMS roughness of $136 \pm 8 \mathrm{~nm}$.
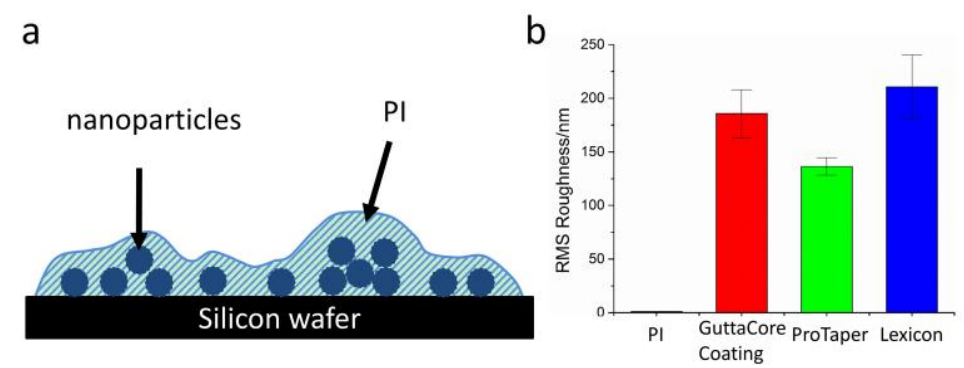

Figure 6. (a) Schematic illustration of a typical Gutta-percha nanocomposite scaffolds; (b) RMS roughness of PI, GuttaCore ${ }^{\mathrm{TM}}$ Coating, ProTaper ${ }^{\mathrm{TM}}$ and Lexicon ${ }^{\mathrm{TM}}$ samples calculated from the SPM topographical images. Note the value for PI, $1.2 \pm 0.1 \mathrm{~nm}$ is too small to appear clearly.

\section{Conclusions}

In this study, we have demonstrated that the $\mathrm{ZnO}$ nanoparticles in the scaffolds obtained from Gutta-percha nanocomposites were encapsulated within the polymer matrix. No significant anti-bacterial or cytotoxic effects could be determined. DPSC plated on these scaffolds were shown to proliferate and differentiate without additional soluble factors after 21-day incubation. Hence the mechanical strength and roughness imparted by the nanoparticles contributed to promoting differentiation of DPSC placed in contact with the material surfaces. These results indicate that in addition to obturation, Gutta-percha nanocomposites ProTaper ${ }^{\mathrm{TM}}$, Lexicon ${ }^{\mathrm{TM}}$, and GuttaCore ${ }^{\mathrm{TM}}$ may also be used as scaffolds for tooth regeneration.

Acknowledgments: We gratefully acknowledge support from an NSF-Inspire grant DMR-1344267, and the Thermomechanical \& Imaging Nanoscale Characterization (ThINC) facility.

Author Contributions: Miriam Rafailovich, Liudi Zhang, Christopher Joubert, George Bruder, Marcia Simon, and Stephen G. Walker conceived and designed the experiments; Liudi Zhang, Yingiie Yu, Ying Liu, and Chung-Chueh Chang performed the experiments; Miriam Rafailovich and Liudi Zhang analyzed the data; Marcia Simon and Stephen G. Walker contributed reagents and materials; Liudi Zhang wrote the paper; Miriam Rafailovich, Marcia Simon, and Stephen G. Walker revised the paper.

Conflicts of Interest: The authors declare no conflict of interest. The founding sponsors had no role in the design of the study; in the collection, analyses, or interpretation of data; in the writing of the manuscript, and in the decision to publish the results.

\section{References}

1. Cohen, S.; Hargreaves, K.M. Pathways of the Pulp, 9th ed.; Mosby Elsevier: St. Louis, MO, USA, 2006; pp. 499-565.

2. Carrotte, P. Endodontics: Part 1. The modern concept of root canal treatment. Br. Dent. J. 2004, 197, 181-183. [CrossRef] [PubMed]

3. Patel, S.; Barnes, J.J.; Manogue, M. The Principles of Endodontics, 2nd ed.; Oxford University Press: Oxford, UK, 2013; pp. 23-52. 
4. Dietschi, D.; Duc, O.; Krejci, I.; Sadan, A. Biomechanical considerations for the restoration of endodontically treated teeth: A systematic review of the literature-Part 1. Composition and micro- and macrostructure alterations. Quintessence Int. 2007, 38, 733-743. [PubMed]

5. Dietschi, D.; Duc, O.; Krejci, I.; Sadan, A. Biomechanical considerations for the restoration of endodontically treated teeth: A systematic review of the literature, Part II (Evaluation of fatigue behavior, interfaces, and in vivo studies). Quintessence Int. 2008, 39, 117-129. [PubMed]

6. Alrahabi, M.K.; Ali, M.M. Root canal revascularization. The beginning of a new era in endodontics. Saudi Méd. J. 2014, 35, 429-434. [PubMed]

7. Kitamura, C.; Nishihara, T.; Terashita, M.; Tabata, Y.; Jimi, E.; Washio, A.; Hirata, S. Regeneration approaches for dental pulp and periapical tissues with growth factors, biomaterials, and laser irradiation. Polymers 2011, 3, 1776-1793. [CrossRef]

8. Oshima, M.; Tsuji, T. Whole tooth regeneration as a future dental treatment. Adv. Exp. Med. Biol. 2015, 881, 255-269. [PubMed]

9. Garcia-Godoy, F.; Murray, P.E. Recommendations for using regenerative endodontic procedures in permanent immature traumatized teeth. Dent. Traumatol. 2012, 28, 33-41. [CrossRef] [PubMed]

10. La Noce, M.; Paino, F.; Spina, A.; Naddeo, P.; Montella, R.; Desiderio, V.; de Rosa, A.; Papaccio, G.; Tirino, V.; Laino, L. Dental pulp stem cells: State of the art and suggestions for a true translation of research into therapy. J. Dent. 2014, 42, 761-768. [CrossRef] [PubMed]

11. Ledesma-Martinez, E.; Mendoza-Nunez, V.M.; Santiago-Osorio, E. Mesenchymal stem cells derived from dental pulp: A review. Stem Cells Int. 2016, 2016, 4709572. [CrossRef] [PubMed]

12. D’Aquino, R.; De Rosa, A.; Lanza, V.; Tirino, V.; Laino, L.; Graziano, A.; Desiderio, V.; Laino, G.; Papaccio, G. Human mandible bone defect repair by the grafting of dental pulp stem/progenitor cells and collagen sponge biocomplexes. Eur. Cells Mater. 2009, 18, 75-83.

13. Giuliani, A.; Manescu, A.; Langer, M.; Rustichelli, F.; Desiderio, V.; Paino, F.; de Rosa, A.; Laino, L.; d'Aquino, R.; Tirino, V.; et al. Three years after transplants in human mandibles, histological and in-line holotomography revealed that stem cells regenerated a compact rather than a spongy bone: Biological and clinical implications. Stem Cells Transl. Med. 2013, 2, 316-324. [CrossRef] [PubMed]

14. Wang, J.; Liu, X.; Jin, X.; Ma, H.; Hu, J.; Ni, L.; Ma, P.X. The odontogenic differentiation of human dental pulp stem cells on nanofibrous poly(L-lactic acid) scaffolds in vitro and in vivo. Acta Biomater. 2010, 6, 3856-3863. [CrossRef] [PubMed]

15. Piva, E.; Silva, A.F.; Nor, J.E. Functionalized scaffolds to control dental pulp stem cell fate. J. Endod. 2014, 40, S33-S40. [CrossRef] [PubMed]

16. Paduano, F.; Marrelli, M.; White, L.J.; Shakesheff, K.M.; Tatullo, M. Odontogenic differentiation of human dental pulp stem cells on hydrogel scaffolds derived from decellularized bone extracellular matrix and collagen type I. PLoS ONE 2016, 11, e0148225. [CrossRef] [PubMed]

17. Gennari, C. Differential effect of glucocorticoids on calcium absorption and bone mass. Br. J. Rheumatol. 1993, 32, 11-14. [CrossRef] [PubMed]

18. Chang, C.; Bherwani, A.; Simon, M.; Rafailovich, M.; Jurukovski, V. Entangled polymer surface confinement, an alternative method to control stem cell differentiation in the absence of chemical mediators. Ann. Mater. Sci. Eng. 2014, 1, 1-7.

19. Kemp, A.R.; Peters, H. Fractionation and molecular weight of rubber and Gutta-percha. Ind. Eng. Chem. 1941, 33, 1391-1398. [CrossRef]

20. Friedman, C.M.; Sandrik, J.L.; Heuer, M.A.; Rapp, G.W. Composition and mechanical properties of Gutta-percha endodontic points. J. Dent. Res. 1975, 54, 921-925. [CrossRef] [PubMed]

21. Maniglia-Ferreira, C.; Gurgel-Filho, E.D.; de Araujo Silva, J.B., Jr.; de Paula, R.C.; de Andrade Feitosa, J.P.; de Sousa-Filho, F.J. Chemical composition and thermal behavior of five brands of thermoplasticized Gutta-percha. Eur. J. Dent. 2013, 7, 201-206. [CrossRef] [PubMed]

22. Zehnder, M.; Guggenheim, B. The mysterious appearance of enterococci in filled root canals. Int. Endod. J. 2009, 42, 277-287. [CrossRef] [PubMed]

23. Moorer, W.R.; Genet, J.M. Antibacterial activity of Gutta-percha cones attributed to the zinc oxide component. Oral Surg. Oral Med. Oral Pathol. 1982, 53, 508-517. [CrossRef]

24. Kołodziejczak-Radzimska, A.; Jesionowski, T. Zinc oxide-From synthesis to application: A review. Materials 2014, 7, 2833-2881. [CrossRef] 
25. Jeng, H.A.; Swanson, J. Toxicity of metal oxide nanoparticles in mammalian cells. J. Environ. Sci. Health Part A Toxic Hazard Subst. Environ. Eng. 2006, 41, 2699-2711. [CrossRef] [PubMed]

26. Sahu, D.; Kannan, G.M.; Vijayaraghavan, R.; Anand, T.; Khanum, F. Nanosized zinc oxide induces toxicity in human lung cells. ISRN Toxicol. 2013, 2013, 316075. [CrossRef] [PubMed]

27. Ivask, A.; Juganson, K.; Bondarenko, O.; Mortimer, M.; Aruoja, V.; Kasemets, K.; Blinova, I.; Heinlaan, M.; Slaveykova, V.; Kahru, A. Mechanisms of toxic action of $\mathrm{Ag}, \mathrm{ZnO}$ and $\mathrm{CuO}$ nanoparticles to selected ecotoxicological test organisms and mammalian cells in vitro: A comparative review. Nanotoxicology 2014, 8 , 57-71. [CrossRef] [PubMed]

28. Pascon, E.A.; Spangberg, L.S. In vitro cytotoxicity of root canal filling materials: 1. Gutta-percha. J. Endod. 1990, 16, 429-433. [CrossRef]

29. Gambarini, G.; Testarelli, L.; Al-Sudani, D.; Plotino, G.; Grande, N.M.; Lupi, A.; Giardina, B.; Nocca, G.; de Luca1, M. In vitro evaluation of the cytotoxicity of different root canal filling materials. Open Dent. J. 2011, 5, 29-32. [CrossRef] [PubMed]

30. Batouli, S.; Miura, M.; Brahim, J.; Tsutsui, T.W.; Fisher, L.W.; Gronthos, S.; Robey, PG.; Shi, S. Comparison of stem-cell-mediated osteogenesis and dentinogenesis. J. Dent. Res. 2003, 82, 976-981. [CrossRef] [PubMed]

31. Gronthos, S.; Mankani, M.; Brahim, J.; Robey, P.G.; Shi, S. Postnatal human dental pulp stem cells (DPSCs) in vitro and in vivo. Proc. Natl. Acad. Sci. USA 2000, 97, 13625-13630. [CrossRef] [PubMed]

32. Bodrumlu, E.; Alacam, T. Evaluation of antimicrobial and antifungal effects of iodoform-integrating Gutta-percha. J. Can. Dent. Assoc. 2006, 72, 733. [PubMed]

33. Jhamb, A.; Chaurasia, V.R.; Masamatti, V.K.; Agarwal, J.H.; Tiwari, S.; Nair, D. In vitro evaluation of antimicrobial activity of different Gutta-percha points and calcium hydroxide pastes. J. Int. Soc. Prev. Community Dent. 2014, 4, 92-95. [CrossRef] [PubMed]

34. Alliot-Licht, B.; Bluteau, G.; Magne, D.; Lopez-Cazaux, S.; Lieubeau, B.; Daculsi, G.; Guicheux, J. Dexamethasone stimulates differentiation of odontoblast-like cells in human dental pulp cultures. Cell Tissue Res. 2005, 321, 391-400. [CrossRef] [PubMed]

35. Iaculli, F.; Di Filippo, E.S.; Piattelli, A.; Mancinelli, R.; Fulle, S. Dental pulp stem cells grown on dental implant titanium surfaces: An in vitro evaluation of differentiation and microRNAs expression. J. Biomed. Mater. Res. B 2016. [CrossRef] [PubMed]

(C) 2016 by the authors; licensee MDPI, Basel, Switzerland. This article is an open access article distributed under the terms and conditions of the Creative Commons Attribution (CC-BY) license (http://creativecommons.org/licenses/by/4.0/). 